\title{
Research on health priorities: a regional agenda and its implementation in Jordan and Pakistan
}

Ahmed Mandil, ${ }_{1}$ Syed Abbas Motevalian, ${ }^{2}$ Arshad Altaf, ${ }^{3}$ Randa Obeidat, ${ }^{4}$ Nazeema Muthu, ${ }^{5}$ Sabeen Afzal, ${ }^{6}$ Syed Baqar Jafri, ${ }^{7}$ Muhammad Naveed Asghar ${ }^{8}$ and Arash Rashidian ${ }^{9}$

${ }^{1}$ Coordinator, Research and Innovation, World Health Organization Regional Office for the Eastern Mediterranean, Cairo, Egypt. ${ }^{2}$ Professor of Epidemiology, Psychosocial Health Research Institute, Iran University of Medical Sciences, Tehran, Islamic Republic of Iran; Consultant, Science, Information \& Dissemination, World Health Organization Regional Office for the Eastern Mediterranean, Cairo, Egypt. ${ }^{3}$ Technical Officer, Research Promotion \& Development, World Health Organization Regional Office for the Eastern Mediterranean, Cairo, Egypt. ${ }^{4}$ Director, Institutional Development \& Quality Control, Ministry of Health, Amman, Jordan. ${ }^{5}$ Monitoring \& Evaluation Officer, WHO Country Office, Amman, Jordan. ${ }^{6}$ Ministry of National Health Services, Regulation and Coordination, Islamabad, Pakistan. ${ }^{7}$ Technical Officer, WHO Country Office, Islamabad, Pakistan. ${ }^{8} \mathrm{Health}$ Policy and Systems Research Officer, WHO Country Office, Islamabad, Pakistan. ${ }^{9}$ Director, Department of Science, Information and Dissemination, World Health Organization Regional Office for the Eastern Mediterranean, Cairo, Egypt. (Correspondence to: Ahmed Mandil: mandila@who.int).

Citation: Mandil A; Motevalian SA; Altaf A; Obeidat R; Muthu N; Afzal S; et al. Research on health priorities: a regional agenda and its implementation in Jordan and Pakistan. East Mediterr Health J. 2021;27(4):319-320. https://doi.org/10.26719/2021.27.4.319

Copyright $@$ C World Health Organization (WHO) 2021. Open Access. Some rights reserved. This work is available under the CC BY-NC-SA 3.0 IGO license (https://creativecommons.org/licenses/by-nc-sa/3.o/igo).

The Eastern Mediterranean Region (EMR) is facing extraordinary social and health challenges, aggravated by epidemiologic variations, high morbidity and mortality burden (communicable, noncommunicable, injuries), consequences of emergencies (including current COVID-19 pandemic), conflicts and massive migrant population movements (1,2). Research for health is essential for generating necessary evidence, which contributes to sustainable development, economic growth and sound health policy-making. Moreover, research for health that addresses national public health priorities is essential for developing required evidence for explanations that contribute towards health improvement and can assist in best utilization of available resources towards issues that maximize the research impact on population health (3-7).

There are many experiences in EMR countries in conduct of health research priority setting at different levels, using a variety of approaches (8-11). Noting the importance of the issue, WHO published a guide for research priority-setting in 2020 (12). While the guide was focused on enabling WHO staff for such exercises, it includes methods that are of use to the Member States in health research prioritization. In this guidance, the acronym PIPE, which stands for Plan, Implement, Publish and Evaluate, describes the four phases of research priority setting process. The steps are intended to ensure prioritization exercise is well planned to respond to the specific national / local context needs, implemented according to the plan and timetable, and its outcomes are published and widely disseminated among key stakeholders. It also includes processes for monitoring and evaluation to track the implementation on agreed priorities and measure the impact of research prioritization exercises (12).

To enable such activities in countries of the Region, the guide was translated to regional languages (Arabic, French, Farsi and Urdu) and shared with the countries. In addition, pilot national exercises were planned/ implemented in two countries in the EMR - Jordan and Pakistan - in response to national interests in February and March 2021. The objectives were to sensitize participants on the WHO guidance document (12); facilitate dialogue among major stakeholders on national public health research priorities for improving population health; align funding for promotion of public health research; develop a mechanism for monitoring during the implementation phase and ensure that research priority setting is carried out on regular basis. While the Jordan exercise was based on the "Nominal Group Technique" (NGT) (13) for scoring / ranking research statements, the Pakistan one was based on the "Child Health and Nutrition Research Initiative (CHNRI)" (14) technique. The expected outcomes for both exercises were to develop a list of public health research priorities for the next 3-5 years; design a mechanism for carrying out public health research priority exercise on periodic basis; and align funding for the priority public health research areas.

For Jordan, the priority setting exercise was linked with Ministry of Health Strategic Plan (2018-2022) (15) and Jordan National Action Plan for Health Security (2018-2022) (16) with participation of 40 relevant research stakeholders / research experts and in close collaboration with WCO/Jordan and Ministry of Health, while the WHO Eastern Mediterranean Regional Office team from Science, Information and Dissemination department (EMRO/SID) provided technical support using the WHO guidance document (12). The exercise was aimed at development of a short list of research statements for 3 main research areas, i.e. (1) health systems and Universal Health Coverage (UHC); (2) health services, digital health and migration health, and (3) COVID-19 response, including public health surveillance. For Pakistan, the prioritization exercise was linked to the 12th National Five-Year Plan (2018-2023) (17) and WHO's Country Cooperation Strategy 2020-2025 (18), to ensure better health of population through enhanced access to universal health coverage and protection from health emergencies. It was conducted with the involvement of 50 relevant stakeholders that included Ministry of National Health Services, and Regulation and Coordination (MoNHSRC), academic and research institutions from public and private sectors, WHO, and other development partners in the health sector. The priority setting exercise aimed at identifying public health research priorities in 5 thematic areas, i.e. (1) communicable diseases; (2) 
noncommunicable diseases; (3) reproductive, maternal, neonatal, child and adolescent health; (4) health services and systems; and (5) mental health.

Both research priority setting exercises involved development of a long list of research statements as potential national priorities, which were then subjected to participants deliberation, small groups discussions and consensus development to identify the national research priorities. These activities resulted in identifying 30 (in case of Jordan) and 50 (in case of Pakistan) research topics as priorities for health research in these two countries. Future actions are now focused on publishing, and disseminating the research priorities to different stakeholders at national and provincial level, identifying resources to enhance uptake of the research priorities by academic institutions and other partners, and monitoring and evaluation of their impact on research and responding to national needs.

Moving forward, WHO plans to extend such exercises to other Member States in the EMR in order to ensure that resources are well utilized and evidence is generated for high-priority health problems in communities to support health policy-making and sustainable development. To ensure success for such exercises, monitoring and evaluation indicators of achievement are designed to include satisfaction of stakeholders with the priority setting processes; alertness of stakeholders with the priorities and their citation in published reports; change in volume of research funding (compared to baseline during planning); and change in the nature of research conducted at local, provincial and national levels, including novel interventions.

\section{References}

1. Al-Mandhari A. Public health in the Eastern Mediterranean Region: profound challenges, huge opportunities. Lancet. 2019 Sep 21;394(10203):992-993. doi: 10.1016/So140-6736(19)32138-5.

2. Al-Mandhari A. Achieving "Health for All by All" in the Eastern Mediterranean Region. East Mediterr Health J. 2019 Oct 13;25(9):595-596. https://doi.org/10.26719/2019.25.9.595

3. The Bamako call to action: research for health. The Lancet 2008;372(9653):1855.

4. World Health Organization. Technical Paper presented to RC 2019: Developing national institutional capacity for evidence-informed policy-making for health. Cairo: WHO Regional Office for the Eastern Mediterranean; 2019. https://applications.emro. who.int/docs/RC_Technical_Papers_2019_6_en.pdf?ua=1.

5. World Health Organization. The WHO strategy on research for health. Geneva: World Health Organization; 2012 (https://www. who.int/phi/WHO_Strategy_on_research_for_health.pdf).

6. Mandil A; Rashidian A; Hajjeh R. Health research prioritization: global and regional perspectives. East Mediterr Health J. 2020;26(3):254-256 https://doi.org/10.26719/2020.26.3.254 (https://applications.emro.who.int/emhj/v26/03/10203397-2020-2603-254256.pdf?ua=1).

7. Rashidian A, Mandil A, Mahjour J. Improving evidence-informed policy-making for health in the Eastern Mediterranean Region. East Mediterr Health J. 2018;23(12):793-4.

8. Amini M; Kojuri J; Lotfi F; KarimianZ; AbadiASH. Research priorities in medical education in the Eastern Mediterranean Region. East Mediterr Health J. 2012;18(7):687-692 https://doi.org/10.26719/2012.18.7.687 (https://apps.who.int/iris/bitstream/handle/10665/118169/2012_18_7_0687_0692.pdf?sequence=1\&isAllowed=y).

9. Badakhshan A, Arab M, Rashidian A, Gholipour M, Mohebbi E, Zendehdel K. Systematic review of priority setting studies in health research in the Islamic Republic of Iran. East Mediterr Health J 2018, 24(8):753-769. doi: 10.26719/2018.24.8.753.

10. Regan M; Gater R; Rahman A; Patel V. Mental health research: developing priorities and promoting its utilization to inform policies and services. East Mediterr Health J. 2015;21(7):517-521 https://doi.org/10.26719/2015.21.7.517 (https://www.emro.who.int/emhj-volume-21-2015/volume-21-issue-7/mental-health-research-developing-priorities-and-promoting-its-utilization-to-inform-policies-and-services.html).

11. Viergever RF; Olifson S; Ghaffar A; Terry RF. A checklist for health research priority setting: nine common themes of good practice. Health Research Policy and Systems 2010;8:36 (http://www.health-policy-systems.com/content/8/1/36).

12. World Health Organization. A systematic approach for undertaking a research priority-setting exercise. Guidance for WHO staff. Geneva: World Health Organization; 2020 (https://apps.who.int/iris/bitstream/handle/10665/334408/9789240009622-eng. pdf?sequence $=1$ \&isAllowed $=y$ ).

13. Centers for Disease Control and Prevention (CDC). Gaining consensus among stakeholders through the Nominal Group Technique. Atlanta: CDC; 2018 (https://www.cdc.gov/healthyyouth/evaluation/pdf/brief7.pdf).

14. Rudan I; Gibson JL; Ameratunga S; El Arifeen S, Bhutta ZA; et al. Setting priorities in global child health research Investments: guidelines for implementation of CHNRI method. Croat Med J. 2008;49:720-33. doi:10.3325/cmj.2008.49.720 (https://methods. cochrane.org/prioritysetting/blog/child-health-and-nutrition-research-initiative-chnri-approach-research-priority-setting).

15. Hashemite Kingdom of Jordan Ministry of Health. Health Strategic Plan (2018 - 2022) Amman: Ministry of Health; 2018.

16. Hashemite Kingdom of Jordan Ministry of Health. Jordan National Action Plan for Health Security (2018-2022). Amman: Ministry of Health; 2018.

17. Ministry of Planning, Development \& Special Initiatives. 12th National Five-Year Plan (2018-2023). Islamabad: Government of Pakistan; 2018.

18. World Health Organization Regional Office for the Eastern Mediterranean Region (WHO/EMRO). Country cooperation strategy: Pakistan. Cairo:WHO/EMRO; 2018 (https://apps.who.int/iris/bitstream/handle/10665/136607/ccsbrief_pak_en.pdf?sequence $=1$ \&isAllowed $=y$ ). 